\title{
Evaluating Research Efficiency within National R\&D Programmes
}

\author{
Fernando Jiménez-Sáez ${ }^{\mathrm{a} *}$, Jon Mikel Zabala-Iturriagagoitia ${ }^{\mathrm{b}}$, José L. Zofío ${ }^{\mathrm{c}}$ and Elena Castro- \\ Martínez $^{\mathrm{a}}$ \\ ${ }^{a}$ INGENIO (CSIC-UPV), Institute of Innovation and Knowledge Management, Ciudad Politécnica \\ de la Innovación, Edificio 8E. Camino de Vera s/n, 46022 Valencia, Spain. \\ ${ }^{\mathrm{b}}$ CIRCLE, Centre for Innovation, Research and Competence in the Learning Economy, LUCIE- \\ huset, Sölvegatan 16, P.O. Box 117, SE-221 00, Lund, Sweden \\ ${ }^{\mathrm{c}}$ Departamento de Análisis Económico: Teoría Económica e Historia Económica. \\ Universidad Autónoma de Madrid, E-28049 Cantoblanco, Madrid, Spain. \\ fjimenez@ingenio.upv.es
}

\begin{abstract}
Relying on efficiency analysis we evaluate to what extent policy makers have been able to promote the establishment of consolidated and comprehensive research groups to contribute to the implementation of a successful innovation system for the Spanish food technology sector, oriented to the production of knowledge based on an application model. Using data envelopment analysis techniques that allow calculation of a generalized version of the traditional distance function model for productive efficiency, we find pervasive levels of inefficiency and a typology of different research strategies. Among these, in contrast to what has been assumed, established groups do not play the pre-eminent benchmarking role; rather, partially oriented, specialized and "shooting star" groups are the most common patterns. These results correspond with an infant innovation system, where the fostering of higher levels of efficiency and promotion of the desired research patterns are ongoing.
\end{abstract}

Key words: Innovation System Management, Research Efficiency, Data Envelopment Analysis, Spanish Food Technology Program.

\footnotetext{
${ }^{*}$ Corresponding author. Tel: +34-963877048; Fax: +34-963877091; e-mail: fjimenez@ingenio.upv.es
} 


\section{Introduction}

Efficiency analysis has been applied in many fields, but there are fewer examples of its application to study the socioeconomic impact of public R\&D policies (Batterbury, 2006; Chelimsky, 1998; Cozzens, 2002), despite its relevance to evaluation studies (Cook and Scioli, 1972; Cozzens, 2003; Joyce, 1980; Pedersen, 1977; Shapira and Kuhlmann, 2003). This stream of work has been addressed mainly to the design of efficiency measures related to university teaching and research activities - e.g. Beasley (1990, 1995), Cherchye and Vanden Abeele (2005). We develop these ideas, focusing on the role played by particular public R\&D instruments and policies - specifically the R\&D projects financial scheme within Spanish Food Technology Programme (SFTP).

In our efficiency analysis we introduce Data Envelopment Analysis (DEA) techniques necessary to implement Chavas and Cox's (1999) generalized distance function. The generalized distance function allows for enhancement of outputs and contraction of inputs at the benchmark frontier, defined by the performance of the leading research groups. Analysis of efficiency rankings allows us to characterize different categories of research groups and their individual direct roles in generating a multidimensional output $\operatorname{mix}^{1}$ that contributes to the relative success of policy in shaping a comprehensive Spanish Food Innovation System (SFIS).

This work contributes to the literature by illustrating the benefits of using another critical and relatively neglected function of evaluation research, such as efficiency, which in our case is aimed at contributing to the policy learning process by providing policy makers with information on how well research programmes measure up to their particular targets.

In 1986, Spain’s central administration took the decision to fully institutionalize public support for research and development (R\&D) and innovation activities. Within the Spanish R\&D Plan, many

\footnotetext{
${ }^{1}$ We provide a thorough description of this "multidimensional research output mix" later in the paper; however, it can be characterized as the output of R\&D projects in terms of training (measured as completed $\mathrm{PhD}$ theses and trained people), science and technology (ISI articles and registered patents) and socioeconomic output (bilateral R\&D contracts).
} 
public actions have been introduced to foster activities in public research organizations (PRO), technology institutes and business firms. All of these actions or R\&D Programmes, have their particular sectoral objectives, but a common goal of better articulation of the Spanish innovation system (CICYT, 1988), i.e. the creation of a system in which the different agents involved in the innovation process - mainly public $R \& D$ managers, research groups operating in technology centres and universities, and private firms - are closely related through supportive networks (Lundvall, 1988, 1992). The R\&D Programmes were accompanied by several financial tools, addressed to achieving the above-mentioned goal, which, for R\&D projects, provided financial support for research groups in PROs to carry out applied research, embodied mainly in international scientific publications, scientific personnel training, patent applications, etc. which are seen as the most relevant measurable outputs.

In this article we show how research groups supported by the SFTP, have indirectly contributed to this objective by generating a multidimensional research output mix (Godin and Gingras, 2000; Tassey, 2003). The efficient performance of these groups within the innovation system is paramount as they are the providers of new knowledge that eventually should have commercial value for the private sector, and should orient public R\&D managers towards the most suitable allocation of public funding for research to enable business firms to benefit from the knowledge created, enabling them to generate innovations to increase wealth and employment across the whole economy.

We evaluate the SFIS by focusing on the performance of public research groups, normally embedded in research and technology institutes and universities, in fulfilling this knowledge generation and diffusion role -see Olazarán et al. (2004) for a general introduction to the historical roles of research groups in the Spanish R\&D system, and. We adopt an efficiency analysis methodology, which enables us to identify the output production performance of different types of research groups and to check whether it represents a multidimensional, balanced and 
comprehensive output mix (Menrad, 2004). This methodological approach has proved valid when analyzing performance within the Spanish innovation system as Revilla et al. (2003) show for a particular policy instrument known as concerted projects-i.e., collaborative partnerships between companies and public research institutions. Their main result is that large organizations perform better than smaller ones as a result of increasing returns to scale, and therefore the larger the companies and research centres involved in a partnership, the higher the synergy that can be

\section{expected from it.}

The paper is structured as follows. Section 2 discusses the methodological approaches proposed in the literature to justify public intervention in R\&D activities when trying to shape a successful innovation system based on the expected multidimensional and comprehensive roles of research groups. This is followed by a discussion in Section 3 of the institutional framework that characterizes the Spanish innovation system (IS). In particular, we look at public managers - in charge of the design and implementation of R\&D policies, and research groups - responsible for the execution of research activities that will contribute to the system. Section 4 introduces the ParetoKoopmans efficiency measure adopted in this research, and shows how it is rendered operational by exploiting the generalized distance function and the specific DEA techniques that allow the calculation of productive efficiency (Section 5). Section 6 presents our results, outlining and discussing the particularities of the data. Section 7 concludes with an overall assessment of the degree to which Spanish R\&D policy and instruments have succeeded in promoting different patterns of research groups contributing to the establishment of a SFIS.

\section{Public policies and the promotion of research}

Arguments in the Economics of Science and Technological Change that favour public intervention are mainly responding to two opposite streams within this literature: the neoclassical, and the structuralist-evolutionary. According to the former, public intervention rests on the existence of 
market failures; production of new knowledge is associated with positive externalities and, thus, public R\&D policies are justified (Arrow, 1962). The latter approach sees knowledge as an imperfect good that does not satisfy the usual characteristic of non-excludability (David et al., 1994). If we accept the non-rival nature of knowledge, then the agents generating it will be able to appropriate only a small fraction of the social benefit produced, and it will be necessary to foster R\&D activities at above optimal market level to justify public policies supporting these activities. This approach is linked to the systemic view of the innovation process in which the concept of IS is used to justify the existence of different agents and the relationships among them, to carry out innovation activities (Freeman, 1987; Lundvall, 1992). Within a structuralist-evolutionary approach, R\&D public policies, to an extent, respond to the need to strengthen the role and involvement of IS agents (Lipsey and Carlaw, 1998; Metcalfe, 2002).

We rely on the concept and terminology of the IS articulation introduced by Rip and Nederhof (1986), to measure and test the capacity of the SFIS to establish a network of fluent and continuous knowledge flows among public and private agents. This articulation and concept is in line with Gibbons et al.'s (1994) description of the change over in scientific knowledge production from mode I to mode II and the subsequent role of relationships among agents to generate new and economically productive knowledge. Using benchmark efficiency analysis methodology we assess whether the SFTP has succeeded in promoting multidimensional output from the Spanish research groups, in terms of a focus on different research dimensions to ensure the transition to mode II knowledge production, while at the same time strengthening their relationships with private firms within the IS. In this context, and taking into account that diversity and specialization are key aspects of every IS (Jacobs, 1998), we assume different sets of research groups in terms of an efficient research output mix, with each playing a particular and meaningful role within the SFIS. To enable the participation of these different groups and to ensure the emergence of new path breaking groups in line with policy objectives, we need an appropriate management and allocation 
of R\&D funds. It has been acknowledged that in the initial stages of any IS, and in order to maximize its future success, $R \& D$ and innovation policies should be aimed at establishing multiple new research groups or providing "seeding", to afford a mix from which comprehensive and leading groups will emerge (Gerchak and Kilgour, 1999). The research question we address is: to what extent have R\&D projects financed by SFTP become tools suited to the promotion of the productive efficiency in multidimensional research groups?

\section{The institutional framework of the SFTP}

The SFTP was launched in 1988 as part of the $1^{\text {st }}$ National R\&D Plan, and has continued to be an element of all its subsequent announcements. The financial support it receives represents around 5\% of the national R\&D Plan budget (Jiménez-Sáez, 2005). Thus, the importance of evaluating the SFTP in order to assess whether and to what extent its original objectives have been achieved is evident. Based on the resources devoted to the SFTP, the evaluation in this study could serve as a model for the other programmes within the Plan. Also, this analysis will complement other analyses and evaluations in this context (Acosta and Modrego, 2001) and will contribute to filling the gap in Spanish R\&D public policy evaluation.

The SFTP was defined in 1988 as a:

systematic group of research and development projects oriented towards the encouragement of research, technology innovation and development in the Spanish Food Technology sector. It is co-ordinated and complemented by other actions among which the training of specialized personnel $^{2}$ and the establishment of an infrastructure that favours technology transfer from knowledge producing sectors to users stand out. (CICYT, 1988)

\footnotetext{
2 The SFTP originally included in the training of specialized personnel two different outputs: young researchers (grant holders) finalizing their $\mathrm{PhD}$ (thesis writing) and technical support personnel. The data for
} 
There are four milestones along the path to the central goal of the SFTP: (i) training personnel; (ii) support for firm $R \& D$ and innovation activities; (iii) support for research groups' $R \& D$ activities; and (iv) support for technology transfer from research groups to firms. The SFTP, similar to other R\&D Programmes within the Spanish R\&D Plan, was designed to cover all the stages in the innovation process, offering the potential of participation by a wide variety of agents, and fostering co-operation among them. The present study focuses mainly on support for the R\&D activities of research groups.

The initial budget for the Programme announced in 1988 was approximately $€ 45$ million. The highest share of this budget was earmarked for the creation of infrastructures ( $€ 14.7$ million, 33\% of the total budget), and support for R\&D activities ( $€ 12$ million, 26.7\%) through a variety of financial tools. Support for R\&D activities carried out by research groups in PROs went to $R \& D$ projects whose output might be of interest to private firms for commercialization. It also was designed to enable cooperation between research groups and firms through bilateral $R \& D$ contracts forged outside of the SFTP financial scheme. It was expected that both sources of financial support would translate into multidimensional research outputs involving science-technology, training and socioeconomic gains that would be basis of lasting cooperation with the private sector.

\section{The generalized distance function and the measurement of research efficiency}

In this section we characterize the production technology of public research using the generalized graph distance function introduced by Chavas and Cox (1999), showing how it relates to conventional hyperbolic and partially oriented output and input counterparts. We consider a panel of $i=1, \ldots, \mathrm{I}$ research groups transforming input vectors $x_{i}=\left(\mathrm{x}_{1 i}, \ldots, \mathrm{x}_{\mathrm{Ni}}\right) \in \mathfrak{R}_{+}^{\mathrm{N}}$ into output vectors $y_{i}$

the analysis in this paper accounts for both these categories as completed PhD theses and technical trained personnel. 
$=\left(\mathrm{y}_{1 i}, \ldots, \mathrm{y}_{\mathrm{Mi}}\right) \in \mathfrak{R}_{+}^{\mathrm{M}}$. The technology can be represented by the production possibility set: $\mathrm{T}^{t}=$ $\{(x, y): x$ can produce $y\}$, and expressed in equivalent terms through input and output correspondence, $y \rightarrow \mathrm{L}(y, \mathrm{~T}) \subseteq \mathfrak{R}_{+}^{\mathrm{N}}$ and $x \rightarrow \mathrm{P}(x, \mathrm{~T}) \subseteq \mathfrak{R}_{+}^{\mathrm{M}}$, which respectively represent the set of all input vectors which yield $y$ and the set of all output vectors obtainable from $x$, Färe and Primont (1995) and Shephard (1970).

For any given research group it is possible to define the generalized distance function in terms of $\mathrm{T}$ as the maximum expansion of the outputs vector and the reduction in the inputs vector: $\mathrm{D}_{\mathrm{G}}(x, y ; \alpha)=\min \left\{\delta>0:\left(x \delta^{1-\alpha}, y / \delta^{\alpha}\right) \in \mathrm{T}\right\}, \quad x \in \mathfrak{R}_{+}^{\mathrm{N}}, y \in \mathfrak{R}_{+}^{\mathrm{M}}$, where $0 \leq \alpha \leq 1$ represents the relative weight that the distance function places on outputs and inputs -a balanced weight is given by $\alpha=0.5$ as $\alpha /(1-\alpha)=1$. The generalized distance function places a research group at the best practice frontier represented by the boundary of the technology - defined as IsoqT $=\{(x, y):(x, y) \in$ $\left.\mathrm{T},\left(\omega^{1-\beta} x, y / \omega^{\beta}\right) \notin \mathrm{T}, 0<\omega<1,0 \leq \beta \leq 1\right\}$, and can be interpreted as a measure of technical efficiency in the sense of Farrell (1957), i.e. how far is the research group from its reference peers at the frontier. Therefore, if $\mathrm{D}_{\mathrm{G}}(x, y ; \alpha)=1$ for a particular research group, this observation is deemed efficient in defining the production frontier IsoqT, while if $\mathrm{D}_{\mathrm{G}}(x, y ; \alpha)<1$ it is inefficient and, given the technology, it could increase its productive performance by reducing its inputs, while increasing its outputs in the amount $\mathrm{D}_{\mathrm{G}}(x, y ; \alpha)$. However, even where a unitary value of the generalized distance function shows that equiproportional inputs reductions and outputs increases are not feasible, this does not prevent the possibility of individual changes in inputs or outputs. In short, distance functions do not provide performance information consistent with the definition of Pareto efficiency introduced by Koopmans (1951: 60) within the activity analysis model. In terms of the production possibility set, a research group can be said to be efficient if it belongs to the efficient subset of T: Eff $\mathrm{T}=\left\{(x, y):(x, y) \in \mathrm{T},\left(x^{\prime},-y^{\prime}\right) \leq(x,-y) \Rightarrow(x,-y) \notin \mathrm{T}\right\}$ (Färe et al., 1985: 28). 
Thus, if a research group is efficient, it is isoquant, but not conversely efficient, and the measurement of technical efficiency through distance functions, does not characterize efficiency in Koopmans' sense, but in the weaker sense provided by IsoqT.

Finally, in addition to the variable returns to scale case considered in the definition of $\mathrm{D}_{\mathrm{G}}(x, y ; \alpha)$, technology may exhibit global increasing, decreasing and constant returns to scale (CRS). In the last case, the technology is defined by $\hat{\mathrm{T}}=\{(\psi x, \psi y):(x, y) \in \mathrm{T}, \psi>0\}$, while the generalized distance function can be denoted as: $\hat{\mathrm{D}}_{\mathrm{G}}(x, y ; \alpha)=\min \left\{\delta>0:\left(x \delta^{1-\alpha}, y / \delta^{\alpha}\right) \in \hat{\mathrm{T}}\right\}, \quad x \in \mathfrak{R}_{+}^{\mathrm{N}}, y \in \mathfrak{R}_{+}^{\mathrm{M}}$. This function can be also interpreted as a measure of productive efficiency, placing an observation on the benchmark frontier represented by Isoq $\hat{T}=\left\{(x, y):(x, y) \in \hat{\mathrm{T}},\left(\omega^{(1-\beta)} x, y / \omega^{\beta}\right) \notin \hat{\mathrm{T}}, 0<\omega<1,0 \leq \beta \leq\right.$ 1\}. Considering the discussion on the notion of Pareto efficiency already introduced in the VRS case, the efficient subset defines analogously: Eff $\hat{\mathrm{T}}=$ $\left\{(x, y):(x, y) \in \hat{\mathrm{T}},\left(x^{\prime},-y^{\prime}\right) \leq(x,-y) \Rightarrow(x,-y) \notin \hat{\mathrm{T}}\right\}$.

We illustrate the efficiency interpretation of the generalized distance functions assuming VRS and CRS. The production possibility set shown in Figure 1 for $\mathrm{N}=\mathrm{M}=1$ reflects all feasible output-input combinations enabled by the state of the technology and the projections of the particular $i$-th observation $\left(\mathrm{x}_{i}, \mathrm{y}_{\mathrm{i}}\right)$ towards the production frontiers that correspond to both definitions of the generalized distance function. The generalized distance function $\mathrm{D}_{\mathrm{G}}(x, y ; \alpha)$ allows for a flexible course towards the production frontier by taking account of both sides of the production process and setting a direction that simultaneously contracts inputs and expands outputs. As we do not want to stress a particular dimension of the production process when measuring research efficiency, in this study we opted for a neutral direction that weights inputs contraction and outputs expansion equally, i.e. $\alpha=0.5$. In general $\mathrm{D}_{\mathrm{G}}(x, y ; \alpha)$ pushes a particular research unit $\left(\mathrm{x}_{i}, \mathrm{y}_{i}\right)$ to the best practice production frontier Isoq T, e.g. in Figure 1 for $\alpha>0.5$ the generalized distance function 
yields a projection denoted by $\left(\mathrm{x}_{i}^{t+}, \mathrm{y}_{i}^{t+}\right)=\left(\mathrm{x}_{i} \cdot \mathrm{D}_{\mathrm{G}}\left(\mathrm{x}_{i}, \mathrm{y}_{i} ; \alpha\right)^{1-\alpha}, \mathrm{y}_{i} / \mathrm{D}_{\mathrm{G}}\left(\left(\mathrm{x}_{i}, \mathrm{y}_{i} ; \alpha\right)^{\alpha}\right)\right.$. But in this particular illustration, when $\alpha=0.5$, the projection $\left(\mathrm{x}_{i}{ }^{*}, \mathrm{y}_{i}{ }^{*}\right)$ is not only technically efficient, but also constitutes the most productive scale size in the presence of CRS - achieving the highest average product, and therefore it also represents the benchmark production frontier Isoq $\hat{T}$ when $\left(x_{i}, y_{i}\right)$ is projected by $\hat{\mathrm{D}}_{\mathrm{G}}(x, y ; \alpha)$, i.e. because of the productive optimality of $\left(\mathrm{x}_{i}^{*}, \mathrm{y}_{i}{ }^{*}\right)-$ from both a technical and a scale perspective, $\mathrm{D}_{\mathrm{G}}(x, y ; \alpha)$ and $\hat{\mathrm{D}}_{\mathrm{G}}(x, y ; \alpha)$ are equivalent distance functions (for a formal demonstration see Zofío and Prieto, 2006).

On this basis, we can consistently decompose productive efficiency into mutually excluding technical and scale components. Since the VRS generalized distance function can be regarded as a technical efficiency measure: $\mathrm{TE}=\mathrm{D}_{\mathrm{G}}(x, y ; \alpha)$, while the generalized distance function represents productive efficiency: $\mathrm{PE}=\hat{\mathrm{D}}_{\mathrm{G}}(x, y ; \alpha)$, any difference between the two would show that the research group, when projected toward the best practice production frontier, is not situated on the relevant optimal CRS loci that would render it scale efficient and, thus, a productivity maximizer benchmark. Accordingly, it is possible to define a scale efficiency measure as: $\mathrm{SE}(x, y ; \alpha)=\hat{\mathrm{D}}_{\mathrm{G}}(x, y ; \alpha) / \mathrm{D}_{\mathrm{G}}(x, y ; \alpha)$. Therefore, productive efficiency can decomposed into a technical component capturing the distance between a research group and its VRS best practice frontier, and a scale component representing how far this technically efficient projection is from the benchmark frontier represented by the most productive scale sizes, i.e. $\mathrm{PE}=$ $\hat{\mathrm{D}}_{\mathrm{G}}(x, y ; \alpha)=\mathrm{D}_{\mathrm{G}}(x, y ; \alpha) \cdot \mathrm{SE}=\mathrm{TE} \cdot \mathrm{SE}$.

[Figure 1 about here] 
Figure 1 illustrates the generalized distance functions and the equiproportional inputs contraction and outputs expansion. However, this graphical representation does not allow us to illustrate how these distance functions fail to capture potential inefficiency sources that might render an observation inefficient according to Koopmans' (1951) definition. To exemplify this we rely on Figure 2 representing a CRS production possibility set. Figure 2 depicts two inefficient observations $\left(\mathrm{x}_{1 i}, \mathrm{x}_{2 i}, \mathrm{y}_{i}\right), i=1,2$, which are respectively projected to the efficient and isoquant subsets defined for equal efficient outputs amounts by Eff $\hat{\mathrm{L}}\left(y^{*}, \hat{\mathrm{T}}\right)=\left\{x: x \in \hat{\mathrm{L}}\left(y^{*}, \hat{\mathrm{T}}\right), x^{\prime} \leq x \Rightarrow x^{\prime} \notin \hat{\mathrm{L}}\left(y^{*}, \hat{\mathrm{T}}\right),\right\}$ and Isoq $\hat{\mathrm{L}}\left(y / \varpi^{\beta}, \hat{\mathrm{T}}\right)=\left\{x: x \in \hat{\mathrm{L}}\left(y / \varpi^{\beta}, \hat{\mathrm{T}}\right), \varpi^{1-\beta} x \notin \hat{\mathrm{L}}\left(y / \varpi^{\beta}, \hat{\mathrm{T}}\right), 0<\varpi<1,0 \leq \beta \leq 1\right\}$-the former being graphically represented by the solid curve while the latter includes the additional discontinuous line extensions parallel to the axes. With regard to the efficient projection of the first observation using the generalized distance function $\hat{D}_{\mathrm{G}}\left(\mathrm{x}_{1 i}, \mathrm{x}_{2 i}, \mathrm{y}_{i} ; \alpha\right)$, we observe that only equiproportional inputs reduction and outputs expansion are feasible: $\left(\mathrm{x}_{11}^{*}, \mathrm{x}_{21}^{*}, \mathrm{y}_{i}^{*}\right)=\left(\mathrm{x}_{11} \cdot \hat{\mathrm{D}}_{\mathrm{G}}\left(\mathrm{x}_{11}, \mathrm{x}_{21}, \mathrm{y}_{1} ; \alpha\right)^{1-\alpha}, \mathrm{x}_{21}\right.$. $\left.\hat{\mathrm{D}}_{\mathrm{G}}\left(\mathrm{x}_{11}, \mathrm{x}_{21}, \mathrm{y}_{1} ; \alpha\right)^{1-\alpha}, \mathrm{y}_{1} / \hat{\mathrm{D}}_{\mathrm{G}}\left(\mathrm{x}_{11}, \mathrm{x}_{21}, \mathrm{y}_{1} ; \alpha\right)^{\alpha}\right)$. For the second observation whose projection to the frontier lies on the isoquant subset, the first input can be individually reduced by the amount $s_{12}$. Hence, the final benchmark for the efficient subset is $\left(\mathrm{x}_{12}^{*}, \mathrm{x}_{22}^{*}, \mathrm{y}_{i}^{*}\right)=\left(\mathrm{x}_{12} \cdot \hat{\mathrm{D}}_{\mathrm{G}}\left(\mathrm{x}_{12}, \mathrm{x}_{22}, \mathrm{y}_{2} ; \alpha\right)^{1-\alpha}-\mathrm{s}_{12}\right.$, $\left.\mathrm{x}_{22} \cdot \hat{\mathrm{D}}_{\mathrm{G}}\left(\mathrm{x}_{11}, \mathrm{x}_{21}, \mathrm{y}_{1} ; \alpha\right)^{1-\alpha}, \mathrm{y}_{2} / \hat{\mathrm{D}}_{\mathrm{G}}\left(\mathrm{x}_{11}, \mathrm{x}_{21}, \mathrm{y}_{1} ; \alpha\right)^{\alpha}\right)$.

[Figure 2 about here]

The generalized distance functions, defined under VRS and CRS technologies, can be interpreted as measures respectively of technical and productive efficiency excluding the non-equiproportional slack representing individual input excesses and output shortages. In order to evaluate research efficiency based on Koopmans' (1951) definition, in what follows we do not focus only on the 
values corresponding to the CRS and VRS generalized distance functions; we also introduce the necessary notation and develop the DEA techniques that allow the measurement of equiproportional as well as individual inputs reductions and outputs increases, i.e. non-proportional slacks capturing input excesses and output shortages.

\section{Calculating research efficiency by means of DEA}

Here we present the non-parametric DEA techniques that allow us to calculate the efficiency of public research groups operating within the SFTP. This approach approximates the true but unknown technology by means of piecewise linear combinations of the observed data, which constitute a multidimensional production frontier (see Cooper et al. (2000) for an introduction to DEA within a production theory context). The DEA piecewise linear approximation of the technology - including its CRS characterization, is given by:

$\hat{\mathrm{T}}=\left\{(x, y): \sum_{i=1}^{\mathrm{I}} \mathrm{z}_{i} \mathrm{x}_{i n} \leq \mathrm{x}_{n}, n=1, \ldots, \mathrm{N} ; \sum_{i=1}^{\mathrm{I}} \mathrm{z}_{i} \mathrm{y}_{i m} \geq \mathrm{y}_{m}, m=1, \ldots, \mathrm{M} ; \mathrm{z} \in \mathfrak{R}_{+}^{\mathrm{I}}, i=1, \ldots, \mathrm{I}\right\}$,

where $z$ is a intensity vector whose values determine the linear combinations of facets that define the production frontier. Following Cooper et al. (2004), we can render Koopmans' efficiency definition operational by relying on a two phase DEA optimizing procedure. For each research group, our empirical approach to evaluating research efficiency consists of a first phase procedure in which we calculate the efficiency score corresponding to the potential equiproportional reduction/expansion of the input/output vectors, and a second phase when we check whether, once the evaluated unit has been projected to the benchmark value resulting from this first phase, further non-proportional input reductions and outputs expansions are feasible - i.e. whether slacks emerge. When these reductions are feasible, a final benchmark based on the proportional and individual adjustments is achieved. 
Given the technology, calculation of the generalized distance function representing productive efficiency for a particular observation $i$ ' requires solution of the following non-linear program:

$$
\hat{\mathrm{D}}_{\mathrm{G}}\left(x_{i^{\prime}}, y_{i^{\prime}} ; \alpha\right)=\min _{\delta, z_{i^{\prime}}}\left\{\delta:\left(x_{i^{\prime}} \delta^{1-\alpha}, y_{i^{\prime}} / \delta^{\alpha}\right) \in \hat{\mathrm{T}}\right\}
$$

s.t.

$\sum_{i=1}^{\mathrm{I}} \mathrm{z}_{i} \mathrm{x}_{i n} \leq x_{i^{\prime} n} \delta^{1-\alpha}, \quad n=1, \ldots, \mathrm{N}$, $\sum_{i=1}^{\mathrm{I}} \mathrm{z}_{i} \mathrm{y}_{i m} \geq \mathrm{y}_{i^{\prime} m} / \delta^{\alpha}, \quad m=1, \ldots, \mathrm{M}$, $z \in \mathfrak{R}_{+}^{\mathrm{I}}$.

As discussed in Section 4, some frontier observations with $\hat{\mathrm{D}}_{\mathrm{G}}\left(x_{i^{\prime}}, y_{i^{\prime}} ; \alpha\right)=1$ may be weakly efficient in the presence of individual input and output changes, therefore belonging to Isoq $\hat{T}$ but not Eff $\hat{\mathrm{T}}$. To empirically identify the presence of these individual slacks we invoke the following linear programme:

$$
\max _{e_{i^{-},}, s_{i^{\prime}}^{+}}\left\{\sum_{n=1}^{\mathrm{N}} \mathrm{e}_{i^{\prime} n}+\sum_{m=1}^{\mathrm{M}} \mathrm{s}_{i^{\prime} m}\right\}
$$

s.t.

$$
\begin{aligned}
& \sum_{i=1}^{\mathrm{I}} \mathrm{z}_{i} \mathrm{x}_{i n}-\mathrm{e}_{i^{\prime} n}=x_{i^{\prime} n}\left(\delta^{*}\right)^{1-\alpha}, \quad n=1, \ldots, \mathrm{N}, \\
& \sum_{i=1}^{\mathrm{I}} \mathrm{z}_{i} \mathrm{y}_{i m}+\mathrm{s}_{i^{\prime} m}=\mathrm{y}_{i^{\prime} m} /\left(\delta^{*}\right)^{\alpha}, \quad m=1, \ldots, \mathrm{M}, \\
& z_{i^{\prime}} \in \mathfrak{R}_{+}^{\mathrm{I}},
\end{aligned}
$$

where $e_{i \prime n}$ and $s_{i^{\prime} n}$ respectively are the individual input contracting and output enhancing slack variables and $\delta^{*}$ represents the optimal solution when resolving (2). Finally, as shown in the previous section, the productive efficiency measure (2) can be decomposed into a technical efficiency term, represented by the VRS generalized distance function $\mathrm{D}_{\mathrm{G}}(x, y ; \alpha)$, and a scale efficiency term equivalent to the ratio of the former to the latter. $\mathrm{D}_{\mathrm{G}}\left(x_{i^{\prime}}, y_{i} ; \alpha\right)$ can be calculated to 
resolve problem (2), but adding the convexity constraint $\sum_{i=1}^{\mathrm{I}} \mathrm{z}_{i^{\prime}}=1$, which allows for VRS - see Banker et al. (1984). When both values have been determined, the scale efficiency term can be derived by dividing the generalized distance functions defined under CRS (2) by its VRS counterpart.

\section{Evaluating the SFTP}

\subsection{Data}

We constructed a data base including inputs and outputs provided to and generated by the research groups participating in R\&D projects financed by the SFTP between 1988 and 1999. Our analysis is conducted at the micro level. We define our units of analysis or Decision Making Units (DMU) as the various research units ${ }^{3}$ operating within the host PRO (Olazarán et al., 2004). Thus, there may be more than one research group from the same PRO participating in the Programme; all are considered in our analysis.

Our target DMUs include research groups receiving financial and human capital inputs from the Spanish Central Administration to promote applied research within the SFTP. Institutionally, they belong to the Spanish National Research Council (CSIC). We chose to focus on the CSIC groups for two reasons. First, the application of efficiency methodologies requires homogeneity among the units to be evaluated (Cherchye and Vanden Abeele, 2005): the CSIC research groups are all based on the same organizational structures, norms, incentives, etc. Second, CSIC has been engaged in research on food technology since the 1940s through the provision of financial support for applied research. Therefore, when the SFTP was launched in 1988, the CSIC research institutes were the only centres operating in the food technology area that were ready to apply for funding under this new scheme. This resulted in a large percentage (up to 60\%) of the financial support for R\&D 
projects being awarded to CSIC research groups between 1988 and 1991 (Ist Spanish R\&D Plan). Due to this large proportion of R\&D projects awarded to CSIC research groups, the homogeneity of CSIC centres in terms of their internal structure, research behaviour and other contextual variables and especially the absence of teaching duties - we restricted our analysis to these research groups. Data on inputs were gathered from the central administrative body responsible for project management -Dirección General de Enseñanza Superior e Investigación Científica - which is also responsible for collecting, processing and checking the final statements submitted by research groups detailing each project's research outputs. Hence, the indicators employed in our analysis are directly dependent on the structure and procedures included in these final reports. Cook and Reichardt (1986) suggest a similar approach to the acquisition of real data concerning the participation of certain agents in a particular research programme, and this method was also adopted by Van der Meulen and Rip (2000) to evaluate public sector research activities in the Netherlands. We need to address some of the problems related to programmes such as the SFTP in terms of their evaluation. Several scholars have pointed to problems related to evaluation (Van der Meulen and Rip, 2000; Van Raan, 2000): (a) measurement (data gathering) problems, and (b) attribution problems, i.e. "how to determine whether and to what extent the programme caused the results observed” (Treasury Board of Canada, 2002: 6). This latter is a major concern in evaluation. In terms of data, we have to trust the final reporting of the (CSIC) research groups in terms of the results achieved as a result of the funding obtained from the SFTP.

For the purposes of our study we focus on the role of $R \& D$ projects in terms of financial and human capital inputs, and three categories of outputs jointly representing a multidimensional output mix, namely training (number of contracted technician personnel and number of completed $\mathrm{PhD}$ dissertations), science-technology outputs (published international articles included in the SCI

\footnotetext{
${ }^{3}$ We define a research unit as the set of researchers that participates in a research project when at least $75 \%$ of the researchers continue unchanged from project to project. Any individual research group can evolve,
} 
database, and registered patents), and socio-economic outputs (bilateral R\&D contracts with firms). Following Beise and Stahl (1999) we consider that this last type of cooperation, between public research groups and firms, can be seen as additional funding that would not have been raised if the research group had not shown itself to be reliable and successful, demonstrated by the outcomes of previous research activities.

Some explanation for the periodicity in our study is needed. The time period of our analysis, 19881999, covers the first three Spanish R\&D Plans - each of which ran for four years. We do not adopt a four year periodicity, as R\&D projects within the SFTP last for up to three years (CICYT, 1987; Jiménez-Sáez, 2005). A successful research group, which obtains funding every time it applies, i.e. every three years thus overlapping different R\&D Plans, would have a chain of four projects - each of three years' duration - over the 12 year period. Hence, we define four periods for our analysis, covering the natural periodicity of an R\&D project: $1^{\text {st }}$ period: $1988-1990 ; 2^{\text {nd }}$ period: $1991-1993$; $3^{\text {rd }}$ period: $1994-1996$; and $4^{\text {th }}$ period: $1997-1999 .^{4}$ In order to resolve time-lag problems that could exist between R\&D input endowments and output production, we decided on a forward moving average which calculates output production in a given period $t$ as the average between the outputs produced in periods $t$ and $t+1 .^{5}$ This smooths outputs over the 12 year period considered, reducing the effects of misallocation on output variability, over the four periods. This gives us a sample

\footnotetext{
decompose into or merge with a new or different research group, according to our definition.

${ }^{4}$ In terms of the problems related to the time lag between inputs endowment and outputs production, and the attribution of certain outputs to a particular time period, studies of productive efficiency in university departments and R\&D managers in official agencies (Beasley, 1990, 1995; Cherchye and Vanden Abeele, 2005; Martínez Cabrera, 2003) face similar problems. With regard to the SFTP we conclude that the schedule of the R\&D agency responsible for the management of the programme, i.e. 3 years, is sufficiently long to establish a link between inputs usage and the results obtained. In any case, it should be borne in mind that the environmental conditions for outputs are the same across all research units (e.g. delays over publication of articles, time for patent registration, viva for doctoral thesis, etc.), so for efficiency measurements over period of time considered here there is a level playing field.

${ }^{5}$ For the last period 1997-99 we do not calculate the moving average since we do not have data on the subsequent period (00-02), but it would be reasonable to assume that the next period's outputs would remain unchanged, and the moving average under this assumption would yield the same result.
} 
population of 64 CSIC research groups, of which 42 participate in the first period, 46 in the second period, 49 in the third period and 36 in the last period.

Preliminary descriptive statistics ${ }^{6}$ are shown in Table 1 which summarizes the variables used in the analysis, classified under input and output categories.

[Table 1 about here]

In terms of inputs, based on number of research groups, both number of personnel and overall budget devoted to the SFTP, decline markedly from the first to the last period. From an output perspective, there is a marked growth in the number of contracts forged between research groups and private firms to diffuse and apply the results of research output. This may be an indication of the efforts of Spanish public research bodies to contribute to the articulation of the SFIS. The average private funding per contract received by the research groups in the 1988-1990 period amounted to $€ 18680.9$, rising to $€ 49788.5$ in the last period, which represents an average annual growth rate of $9.3 \%$ and cumulates to $166.5 \%$ over the whole 12 years. This increase in private funding is in sharp contrast to the trend in public funding of R\&D projects, which reflects the shortages in public finance in the SFTP over this period, and the efforts and success of research groups with reliable results and credibility in rising private funding for their research activities (García-Martínez and Briz, 2000). We tested to what extent CSIC research groups are able to make efficient use of diminishing budgets, and whether traditional mode I research behaviour is changing towards mode II.

\footnotetext{
${ }^{6}$ Note that our data set has several zero entries on the outputs side, which is a fundamental characteristic of the decision-making process of research groups, i.e. the result of conscious behaviour. From a computational point of view, we follow the theoretical results presented in Thomson et al. (1993), who state that if a complementary pattern of input or output zeros exists, then the DEA efficiency measures of the DMU's subdomain, obtained by excluding those presenting variables with zero values, are the same as those for the complete data domain including all DMUs -Theorem 9A in Charnes et al. (1991).
} 
In terms of the output variables related to training, the number of trained people and number of doctoral theses show no noticeable increases. On average, the number of trained people within the research groups remained constant at around 4.5 during the first three periods, increasing to 6.3 in the last period. The number of PhD theses was similarly stable at around 2.1 per research group between 1988 and 1996 (first three periods), but decreased to 1.4 in the last period. Finally, in terms of the variables representing science and technology outputs, number of patents and training show similar trends, while scientific articles published in international journals shows a cumulated $8.9 \%$ rate of growth in the four periods, rising on average from 8.3 in the first period, to 11.7 in 1997 1999.

Besides individual efficiency rankings, we analyse the type of research output mix of CSIC research groups through their participation in the SFTP. In terms of financial support and recruitment of capable human resources to conduct research activities, they contribute to the SFTP in three output areas: specialized in a particular dimension, partial when two of the three output dimensions are considered, or a comprehensive research output mix. Our hypothesis is that the higher the efficiency score, along with output production in all research categories, the more comprehensive will be the research group. However, we acknowledge the important role played within the IS by other research groups that may eventually show lower efficiency scores, generating outputs in several categories or being specialized in just one. For example, many different research patterns might be financed in the hope that consolidated and efficient research groups will eventually emerge. Therefore, financial support should be available for all possible research categories, but bearing in mind the opportunity costs that such a pattern of funding might have in terms of research inefficiency and productivity losses (Gerchak and Kilgour, 1999). If support is channelled towards specialized groups, researching in a specific area, this will encourage behaviours that will not facilitate the transition from mode I to mode II knowledge production, and will provide a less than optimal contribution to an integrated IS. Bearing in mind that the SFTP is aimed at creating a critical mass of research in 
this field, it is understandable that policy makers assume that these opportunity costs will favour the establishment and consolidation of the SFIS.

\subsection{Efficiency results}

Our analysis is based on CSIC research group taxonomy (Fernández-de-Lucio et al., 2003; JiménezSáez, 2005). Using DEA techniques we try to determine cross-sectional features and time efficiency trends for each group, and check our main hypothesis that R\&D decision makers within the SFTP have been able to promote the creation and consolidation of an IS based on research groups that undertake a comprehensive range of research activities.

The results for research groups participating in the SFTP that have been efficient in at least one period are presented in Table 2. As described in Section 4, constant (CRS), variable (VRS) and scale efficiency scores are computed to solve the corresponding generalized distance functions, as in equation (2), with and without the convexity constraint. These results show the degree of efficiency of each research group over a given time period, and the stability of the production frontier defined by the efficient groups. On average, the mean value of the efficiency rate along the four periods under CRS, is 0.69 (0.77 assuming VRS), with average standard deviations of 0.25 (and 0.22) respectively. This demonstrates the broad differences that exist among the different research groups participating in the SFTP, and the wide margins for efficiency improvement. Only 19 of the 64 research groups participated in the four periods under study, i.e. only $28 \%$ of the research groups applying to the SFTP show continuity over time, raising doubts about the strengths of these groups. Of these $28 \%$, only two, IF-03 and IG-02, were consistently efficient over the entire 12 year period.

These results to an extent confirm our hypothesis that the support provided by SFTP is promoting a change towards the establishment of a solid IS in Spain. These two groups, which show the highest efficiency scores, produce research output in the three categories and are considered to be the most 
consolidated research groups within the SFIS. In addition, they belong to the most important public research centres, with strong connections with firms and technology institutes, as evidenced by the number of contracts signed with these organizations.

[Table 2 about here]

Next we focus on the results related to the efficiency of those CSIC research groups participating in the SFTP, which are efficient in at least one of the four periods covered. In terms of the inefficient research groups, their mean values remain more or less constant over time (0.605 - CRS - in the first period and 0.612 - CRS - in the last). Similarly, scale efficiency is generally homogenous, although minimum values show an increase over the period. In other words, the SFTP has helped CSIC groups to increase their efficiency. We focus on those research groups that are consistently driving the frontier while performing a comprehensive role within the SFTP and, which, from a policy perspective, can be seen therefore as a benchmark for the other groups. ${ }^{7}$ Of the 64 CSIC research groups in the sample, 12 are considered efficient in the first period under CRS, 11 in the second, 7 in the third and 12 in the fourth. A cross-section perspective allows us to see whether their research activity is comprehensive or whether they are specialized in any of the input and output dimensions included in the analysis. A time perspective allows us to judge whether they can be considered consolidated, emerging, or one-period "shooting stars".

The information presented in Table 3 allows us to characterize each efficient research group within the different research categories. ${ }^{8}$ On the inputs side, we can see the amounts required by each efficient group as a percentage of the minimum amount of inputs employed across all efficient

\footnotetext{
${ }^{7}$ In order to characterize the environmental factors that might explain the efficient or non-efficient patterns (Fried et al., 1999, 2002) we designed a questionnaire that is currently being administered to the research groups participating in the SFTP. The responses to this questionnaire will provide information on qualitative aspects which should help our interpretation of the different patterns we found.

${ }^{8}$ For reasons of space, only the specifications observed in the first and the last period are included in Table 3.
} 
groups - e.g. in the first period the amount of public funding received by CEBAS-02, €37 022, exceeded by $24.3 \%$ the minimum amount of $€ 29780$ employed by IATA- 04 . Consequently, if an efficient group uses the lowest amounts of any given input, it will be shown to be efficient, with a zero value for that input dimension. Correspondingly, for outputs we can see the amount of outputs achieved by each efficient group as a percentage of the maximum amounts attained in the same period - e.g. in the first period CEBAS-02 published 10.7\% (4) fewer international papers than the efficient group with the most publications in this period, in this case IG-02 with 37 publications. Accordingly, if an efficient group achieves the highest amount of any output it will score 100 for that output dimension.

In the first period, IATA-02 had fewer FTE personnel (2), while IATA-04 used the least public funding (€29 780). Overall, these are small research groups, which despite being classed as efficient based on the CRS specification, are not making a real contribution to a comprehensive SFIS. More relevant outputs are: IATA-03 training the highest number (22) of scientific personnel; IG-02 achieving the highest number (6) of completed $\mathrm{PhD}$ theses and the highest number of international publications (37); and IF-03 with the highest number of patents (4) and cooperative contracts (€139693), in the period. In addition to groups that are efficient by default as a result of using the minimum amounts of inputs or achieving the maximum amounts of outputs, there is a set of groups that includes IATA-07, IG-03, IG-05 and INB-01, which, in relative DEA terms, produce an efficient proportion of outputs to inputs. This characterization can be applied to all four periods to allow some inferences about the strategies of these groups, i.e. using the minimum amount of inputs, focusing on specialization to obtain the maximum amounts of outputs, using relatively lower levels of inputs to obtain significant outputs; we show the values for the initial and final periods (Table 3). For example, in the second period CEBAS-05 and IFI-05, employ fewer personnel, and use smaller amounts of funding respectively, while IATA-02, IF-03 and IG-05 obtain the highest outputs. 
[Table 3 about here]

In the third period IPLA-01 and IQOG-02 use lower levels of inputs and IF-03, IFI-08 and IG-04 achieve the highest levels of outputs. Finally, in 1997-1999 period, IATA-06, IF-01 and IIM-01 used the lowest levels of inputs, and IF-03, IG-02 and IG-10 achieved the highest outputs. It is possible to identify different strategies and new emerging research groups, which are improving their competitive positions over time, and other groups with decreasing performance.

\subsection{Alternative research strategies}

Over the time periods analysed, and based on the evolution and research features of efficient and inefficient groups, four categories of groups emerge: time consolidated groups performing multidimensional research, specialized groups (training, science and technology, socioeconomic); partially oriented groups focusing on two output dimensions, and "shooting stars". The consolidated research groups include those observed to be efficient over several periods, with in depth knowledge of the SFIS, and producing outputs in all dimensions. Specialized groups are those research groups that are consistently efficient, and thus are clearly following a research strategy oriented towards the achievement of particular goals in one of the three output dimensions in our analysis. Partially oriented research groups are those whose activities are directed towards the two output dimensions that characterize mode I scientific knowledge production, i.e. training and science and technology. Finally, "shooting stars" describes those efficient research groups that sporadically participate in the SFTP with the objective of achieving a particular goal (i.e. based on presence of PhDs, bilateral contracts with firms, etc.), but which, having achieved their goal, "disappear" in part due to the fact that their research is not really aligned to the food technology area. Table 4 summarizes the typologies of the efficient and inefficient research groups according to 
their multi or partial research output orientation, allowing differentiation among the diverse research groups within the SFTP, which should enable policy makers to assess the financial support embedded in different R\&D projects in order to optimize allocation of SFTP funding according to the specific circumstances and needs of the SFIS.

[Table 4 about here]

We also look at the performance of the multidimensional and time consolidated research groups, which constitute the backbone of the SFIS. We highlight some of the main features of those groups considered to be representative of the specialized, partial and "shooting stars" research groups. Within the consolidated category, there are five research groups. Only one of these is efficient over time, IF-03: ${ }^{9}$ it is efficient in all four periods and achieves high values in most outputs categories. In order to achieve and maintain these standards of output mix production within the system, these groups use substantial amounts of inputs, but they manage them efficiently. They are not specialized in any one single output, and engage in comprehensive research activity, participating in all three output dimensions in all four periods, achieving first-rate measures (see Table 3). This supports the hypothesis that the higher the efficiency and the more comprehensive the research activity, the more consolidated will be the research group over time, and consequently the higher will be its potential to contribute to the SFTP's objectives. This is exemplified by the numbers of patent applications and contracts with firms related to these groups (see Table 3). With reference to IG-02 and IG-03 their patterns are also regarded as being comprehensive, despite their efficiency levels drop in the second and third periods (see Table 2). IG-02 leaded the PhD dissertation (6) and international publication (38) dimensions during the first period, being also concerned with the

\footnotetext{
${ }^{9}$ IG-02, IG-03 and IF-03 show similar trends and output orientation, although the two IG groups are less efficient in the second and third periods.
} 
registration of patents and bilateral contracts with firms, following the pace of IF-03. Then they lowered its efficiency levels during the second period due to the fact that no $\mathrm{PhD}$ theses were defended. This is related to the personnel, and accordingly to the budget received from the SFTP, which also decreased from 14 in the first period to 11 (personnel) and from $€ 213810$ to $€ 154700$ (funding). Then, the group becomes efficient again in the fourth period mainly due to a better balance between the inputs received from the SFTP and the production of a multidimensional output mix. As to IG-03, the explanation for its decreasing efficiency differs from that of IG-02. During the first period, IG-03 produced a balanced output mix, not leading in any of the dimensions included in our analysis, but producing outputs in all of them. However, during the other three periods, the bilateral contracts they managed to sign with firms decreased from €75 132.53 (first period), to $€ 12212.57$ in the second and even none in the third. So, their declining efficiency is mainly due to these difficulties with the bilateral contracts, as the input dimensions and the other output measures kept almost constant in time. Summing up, two different environmental factors, as the funding received from the SFTP scheme and the signed bilateral contracts with firms, are regarded as having a direct influence on the efficiency levels achieved by these comprehensive research groups.

Only five groups are considered specialized, including IG-05 which ranks among the efficient set in the first period based on an unambiguous strategy of heavy involvement in contracts with firms. Also in the first period IF-03 received the most funding from private contracts, €139 693; however, in the second period IG-05 leads, with €91 915. This niche strategy allows IG-05 to maintain its ranking in the first two periods - from 1988 to 1993, but in the third period its competitive position decreases dramatically (see Table 2). It is overtaken in the ranking by other units following a similar strategy; its efficiency score is 0.198 under CRS (0.249 under VRS), despite being ranked fourth for value of contracts $€ 139056$ (IG-04 is ranked $1^{\text {st }}$ with $€ 570$ 624) in the third period. Although the amount of public funding awarded to IG-05 almost doubled from one period to 
another, from €47 930 in 1991-1993 to €81 978 in 1994-1996, this was not enough for it to remain efficient by default. This negative trend resulted in IG-05 disappearing from the efficient subset and the SFTP, and eventually its participation in programmes ceases altogether.

The third set of research groups represents the middle ground characterized by partial research orientation. Our observations evolve along different paths, with groups trying to consolidate their positions efficiently. This category includes the highest number of research groups in our analysis. We first highlight the evolution of IG-04, IATA-03 and CEBAS-02. Despite their strategies differing over time, they all managed to strengthen their positions. Based on a strategy oriented to producing many different outputs that could qualify it as being multi-dimensional, IG-04 started as a low efficiency unit (0.457 under CRS assumptions and 0.549 with VRS in the first period), improving to 0.7 in the second period. In the third period it achieved efficiency based on bilateral contracts, which amounted to $€ 570624.94$, and this was maintained in the last period with a multidimensional pattern. IATA-03's evolution is similar; it scored for all three outputs categories, its management is efficient in the first period, due in particular to the large numbers of people trained within the unit (22). It maintains this strategy oriented to becoming a multi-dimensional research group over time, in the last period registering as a comprehensive and efficient group following some less efficient years. In the case of CEBAS-02, its efficiency pattern is similar to IATA-03, but the change in its strategic orientation is more defined than in the previous cases. With an initially efficient performance mainly due to its orientation towards training and science and technology results, and following some inefficient years, in the last period its position improved due to a change in its strategy to include contracts with private institutions: it is ranked second for contracting, with €305 085 .

Finally, there is a set of 14 research groups that can be considered "shooting stars", which participated in only one of the four periods under study. Their orientation and efficiency vary, from efficient behaviours, INB-01, to efficiency rates of 0.228 under CRS (0.332 under VRS) by IBMB- 
1 , and 0.341 (0.346) by IMEDEA-01. INB-03's and IMEDEA-01's strategy is to try to produce outputs in all three dimensions, IEG-01 has a clear focus on publishing international papers, while IF-0X and INB-01 (partial orientation) focus on training new graduates, producing PhD theses and publishing results.

Based on these results, we would suggest that DEA would be a good instrument for policy managers to use to determine efficient behaviour and formulate policy recommendations. This would enable consistent measurements of consolidated research groups engaged in comprehensive research activities, and contribute to the SFTP's objectives. It would be ideal if these types of groups defined the research frontier, establishing the benchmark for the other participants in the SFTP. However, and because a standard DEA does not incorporate previously unknown value judgments or a priori information, this does not have to be the case. Our results are based on a standard DEA optimizing procedure which searches for the most favourable weights and, therefore, tends to compare inefficient groups measuring them against those DMUs with a higher degree of similarity in their output orientation. From our analysis, IF-03, IG-02 and IIM-01 can be used as benchmarks for a small percentage of research groups. Ranked as the most consolidated observations, IF-03, IG-02 and IIM-01 show a comprehensive research mix with large outputs; they could not be used as the benchmark for the majority of observations as their activity also includes contracts with private firms. They are clearly producing on a more diversified and larger scale, and are in a league of their own. On the other hand, CEBAS-02 and IQOG-02, which initially are focused on training and science and technology related outputs, and not on private contracts presenting zero values for that variable (see fn 6 for technical details), would constitute a more useful benchmark, as they represent the research pattern that applies to the majority of the research groups. In fact, in the first period CEBAS-02 (with 43\% under CRS and 28\% with VRS) and IQOG-02 (70\% and 76\% respectively) are the most frequent reference for inefficient units. This output orientation is also shared by those research groups considered as benchmarks for the three 
remaining periods. Note that these results do not invalidate our methodological approach; they simply confirm that detailed examination of the alternative efficient research paths that converge on the production frontier is critical for effective policy recommendations. Our DEA analysis identifies a conscious research orientation towards specialization in a single or partial output dimension, which shows remarkable results based on the relative use of inputs - e.g. trained personnel and/or publication of peer-reviewed articles; however, such an orientation ranks low in terms of promoting and encouraging research that contributes to the articulation of a comprehensive IS within the Spanish food and beverage industry.

Finally, we should discuss the inefficient research groups. As already pointed out, their mean values are constant over time (Table 2), while minimum values have increased over the 12 years. This shows that the SFTP has helped CSIC groups to increase their efficiency orientation. Concerning outputs, in the comprehensive and partial categories we can see a balance between the amounts for efficient and inefficient research groups. Within the specialized category, on the other hand, there are more inefficient than efficient groups, especially in terms of emerging and "shooting star" temporal patterns. However, there is an interesting trend in these inefficient research groups. Overall, inefficient groups are oriented towards a partial perspective in their outputs, especially during the first two periods studied. However, over time, these partially oriented groups show a trend towards becoming multi-dimensional, although they remain inefficient. Therefore, although the SFTP policy may not have helped CSIC research groups to greatly increase their efficiency, it has played a role in orienting them towards multiple outputs ${ }^{10}$.

\section{Policy implications and conclusions}

\footnotetext{
${ }^{10}$ In order to measure the relative importance of slack inefficiency on total inefficiency we calculated the each weight for each input and output solving equation (3). We observe that the highest percentage weights are on outputs variables, which characterize alternative research strategies and whose variability is larger than is the
} 
This study demonstrates policymakers the deviations that exist between the IS objectives and the mechanisms (incentive schemes) established to assess research group participation. In particular, the methodology we propose identifies and is able to distinguish research groups' behaviours in terms of research output, which gives support to the design and implementation of the different promotion strategies pursued by the administrative body.

We believe that our efficiency analysis sheds light on the relative success achieved by policy in designing a comprehensive IS, and provides a way of assessing the results and allocating funds for R\&D projects according to the specific characteristics of national programmes.

Since the late 1980s the Spanish Ministry for Education and Science has devoted substantial resources to the articulation of a comprehensive IS through a series of R\&D Plans following the general trend in other EU member states. Taking the SFTP as an example, we have analysed to what extent this policy has contributed to fostering the generation of a multidimensional research output mix among research groups, based on one of the objectives of the Programme to induce a change in research strategy from mode I to mode II knowledge production. We adopted a novel approach based on DEA that relies on the generalized distance function proposed by Chavas and Cox (1999), and demonstrated the validity of this methodology for evaluating whether R\&D policies are fostering the creation and survival of research groups that perform a comprehensive role within the IS. We characterized different categories of efficient research groups participating in the SFTP, and followed their evolution between 1988 and 1999. We identified: i) groups considered to be consolidated and efficient, ii) groups that maintained their relative positions over time by specializing in a given output, iii) groups engaging in partial research activity that improved their skills and managed to become efficient, and iv) groups that disappeared after being efficient in a single period, i.e. "shooting stars".

case for inputs. With regard to patents and contracts in particular, we can conclude that slack inefficiency is not negligible, as it exceeds one-third of overall inefficiency in many periods. 
We show that well established, consolidated research groups have a greater impact on the SFTP's objectives through their remarkable output values in all dimensions: their research is more comprehensive than that of new emerging research groups, which has enabled them to sign more contracts with firms and technology centres, and to license their already submitted patents. However, over the time period of our study only a few research groups had reached the critical size needed for them to be considered "mode II knowledge producers".

We can conclude that the Spanish administration's policy developments through the organization of the SFTP have had limited success in achieving their objectives, and especially efforts to support the $R \& D$ activities of research groups. This is because most research groups are either specialized in just one category (outputs such as publications and patents) or partially oriented (combining some of the three categories in our analysis) and could be making a bigger contribution by cooperating with firms. However, we consider that this behaviour is consistent with the incentive schemes related to the scientific promotion and career structure, which depends on such outputs, and is a disincentive for engagement in more comprehensive activities. Such a strategy is also congruent with an infant IS, which needs a critical mass of research groups in order to grow and consolidate over time. To achieve this critical mass, numerous research groups with different abilities and profiles need to be funded despite the fact that only a small percentage will succeed and contribute to the establishment of a benchmark within the system. Such a strategy of seed funding carries a cost in terms of research inefficiency and productivity losses, which decision makers must be aware of. It should be noted that the value of bilateral contracts in the 12 year period studied has risen, mainly due to the efforts of a small consolidated set of groups. Therefore, a shift in policy priorities to recognize the importance of training personnel who can then work in industry, and the signing of bilateral contracts with firms as a valuable scientific output is recommended in order to reorient activity towards the objectives of the SFTP. 
In addition to the multidimensional and partially oriented efficient groups, we found a large set of new research groups with low efficiency levels. These groups have not become more efficient for two reasons: a) they have suffered from a decrease in Programme budget, which in real terms, taking account of inflation, is substantial; and b) they have not been able to raise funds from private firms to compensate —and in case they were able to raise funds, it would be quite probable that their small size would prevent them from ripping the benefits of these partnerships, as suggested by Revilla et al. (2003). As a result these new groups led by young researchers from mature research groups have not been able to consolidate their positions, illustrated by the "shooting stars" pattern. Their results are insignificant in terms of training and science and technology outputs. However, although the SFTP policy overall may not have helped these research groups to increase their efficiency, it has played a role in shifting their orientation from partial towards multiple output production. Therefore, they should receive special attention from the SFTP managers so that in future they can achieve the desired returns in terms of outputs per unit of invested inputs, and can contribute to the Programme's goal in the medium term. More financial resources and the matching of research groups to business firms will be necessary to change research habits from mode I to mode II knowledge production and contribute to the consolidation of the SFIS in the long run. According to our classification there are only two comprehensive and efficient research groups compared with 14 identified as "shooting stars". There are several possible reasons for these findings. The SFIS is young and needs to accommodate different research strategies in order to promote the emergence of long-term comprehensive groups. It is understandable, therefore, that the funds allocation scheme followed by the administration body allows for different research strategies which may pursue (or not) the policy's objective. However, as the optimum policy is utopian, this scheme should vary over time to avoid inefficient "shooting stars" behaviour and encourage a more comprehensively-oriented promotion of knowledge creation that focuses on the needs of the food and beverage sector. García-Martínez and Briz (2000) argue in favour of greater government 
intervention within the SFIS through new policy mechanisms aimed at encouraging and improving firms' interested in innovation. Our study supports this argument, since consolidation of the SFIS to a large extent rests on the technology transfer processes represented by bilateral contracts with firms. 


\section{References}

Acosta Ballesteros, J., Modrego Rico, A., 2001. Public financing of cooperative R\&D projects in Spain: the Concerted Projects under the National R\&D Plan. Research Policy 30, 625-641.

Arrow, J.K., 1962. Economic welfare and the allocation of resources for inventions, in: Nelson, R. (Ed.), The rate and direction of inventive activity: economic and social factor. Princeton University Press and NBER, Princeton.

Banker, R.D., Charnes, A., Cooper, W.W., 1984. Some Models for Estimating Technical and Scale Inefficiencies in Data Envelopment Analysis. Management Science 30(9), 1078-1092.

Batterbury, S., 2006. Principles and Purposes of European Union Cohesion Policy Evaluation. Regional Studies 40(2), 179-188.

Beasley, J.E., 1990. Comparing University Departments. Omega 18(2), 171-183.

Beasley, J.E., 1995. Determining Teaching and Research Efficiencies. Journal of Operational Research Society 46, 441-452.

Beise, M., Stahl, H., 1999. Public research and industrial innovations in Germany. Research Policy 28, 397-422.

Charnes, A., Cooper, W.W., Thrall, R.M., 1991. A Structure for Classifying and Characterizing Efficiencies and Inefficiencies in Data Envelopment Analysis. Journal of Productivity Analysis 2, 197-237.

Chavas, J.P., Cox, T.M., 1999. A Generalized Distance Function and the Analysis of Production Efficiency. Southern Economic Journal 66(2), 295-318.

Chelimsky, E., 1998. The Role of Experience in Formulating Theories of Evaluation Practice. American Journal of Evaluation 19(1), 35-55.

Cherchye, L., Vanden Abeele, P., 2005. On Research Efficiency. A micro-analysis of Dutch university research in Economics and Business Management. Research Policy 34, 495-516.

CICYT, 1988. Plan Nacional de Investigación Científica y Desarrollo Tecnológico 1988-1991, Ministerio de Educación y Ciencia, Secretaría de Estado de Universidades e Investigación, Madrid.

Cook, T.J., Scioli, F.P.Jr., 1972. A Research Strategy for Analyzing the Impacts of Public Policy. Administrative Science Quarterly 17(3), 328-339. 
Cook, T.D., Reichardt, CH.S., 1986. Métodos cualitativos y cuantitativos en investigación evaluativa. Translated by Guillermo Solana "Qualitative and quantitative methods in evaluation research", Sage Publications, 1982.

Cooper, W.W., Seiford, L.M., Tone, K., 2000. Data Envelopment Analysis. A Comprehensive Text with Models, Applications, References and DEA-Software, Kluwer Academic Publishers, Boston.

Cooper, W.W., Seiford, L.M., Zhu, J., 2004. Handbook on Data Envelopment Analysis, Kluwer Academic Publishers, Norwell (Massachussets).

Cozzens, S.E., 2002. Research assessment: what's next? final report on a workshop. Research Evaluation 11(2), 65-79.

Cozzens, S.E., 2003. Frameworks for evaluating S\&T policy in the United States, in: Shapira, P., Kuhlmann, S. (Eds.), Learning from Science and Technology Policy Evaluation. Edward Elgar, Cheltenham, pp. 54-64.

David, P., Mowery, D., Steinmueller, W.E., 1994. Analyzing the economic payoffs from basic research, in: Mowery, D. (Ed.), Science and Technology Policy in Interdependent Economies. Kluwer Academic Publishers, Boston, pp. 57-78.

Färe, R., Grosskopf, S., Lovell, C.A.K., 1985. The Measurement of Efficiency of Production, Kluwer Nijhoff Publishing, Boston.

Färe, R., Primont, D., 1995. Multi-Output Production and Duality: Theory and Applications, Kluwer Academic Publishers, Boston.

Farrell, M., 1957. The Measurement of Productive Efficiency. Journal of the Royal Statistical Society. Series A, General 120(3), 253-281.

Fernández-de-Lucio, I., Jiménez-Sáez, F., Castro-Martínez, E., Gutiérrez-Gracia, A., 2003. The evaluation of the National Food Technology Programme: the articulation of the Spanish food innovation system. International Journal of Agricultural Resources, Governance and Ecology 2(3/4), 343-359.

Freeman, C. 1987. Technology Policy and Economic Performance. Lessons from Japan, Printer Publishers, London. 
Fried, H.O., Schmidt, S.S., Yaisawarng, S., 1999. Incorporating the Operating Environment Into a Nonparametric Measure of Technical Efficiency. Journal of Productivity Analysis 12(3), 249-267.

Fried, H.O., Lovell, C.A.K., Schmidt, S.S., Yaisawarng S., 2002. Accounting for Environmental Effects and Statistical Noise in Data Envelopment Analysis. Journal of Productivity Analysis 17(1-2), 157-174.

García-Martínez, M., Briz, J., 2000. Innovation in the Spanish Food \& Drink Industry. International Food and Agribusiness Management Review 3, 155-176.

Gerchak, Y., Kilgour, D.M., 1999. Optimal parallel funding of research and development projects. IIE Transactions 31(2), 145-152.

Gibbons, M., Limoges, C., Nowotny, H., Schwartzman, S., Scott, P., Trow, M., 1994. The New Production of Knowledge: The Dynamics of Science and Research in Contemporary Societies, Sage Publications, London.

Godin, B., Gingras, Y., 2000. What is Scientific Culture and How to Measure it: a Multidimensional Model. Public Understanding of Science 9, 43-58.

Jacobs, C., 1998. Innovation policies within the framework of internationalization. Research Policy 27, 711-724.

Jiménez-Sáez, F., 2005. Una Evaluación del Programa Nacional de Tecnología de Alimentos: análisis de la articulación fomentada sobre el Sistema Alimentario de Innovación en España, Ph.D. dissertation, Servicio de Publicaciones de la Universidad Politécnica de Valencia, Valencia.

Joyce, L., 1980. Developments in Evaluation Research. Journal of Occupational Behaviour 1(3), 181-190.

Koopmans, T. C., 1951. An analysis of production as an efficient combination of activities, in: Koopmans, T.C. (Ed.), Activity Analysis of Production and Allocation, Cowles Commission for Research in Economics. John Wiley and Sons Inc., New York, Monograph 13.

Lipsey, R., Carlaw, K., 1998. A Structuralist Assessment of Technology Policies - Taking Schumpeter Seriously on Policy, Industry Canada Research Publications Program, Ottawa. 
Lundvall, B.-Å., 1988. Innovation as an interactive process: from user-producer interaction to the national innovation systems, in: Dosi, G., Freeman, C., Nelson, R.R., Silverberg, G., Soete, L. (Eds.), Technical Change and Economic Theory. Pinter, London, pp. 349-369.

Lundvall, B. Å., 1992. National Systems of Innovation. Toward a Theory of Innovation and Interactive Learning, Printer Publishers, London.

Martínez Cabrera, M., 2003. La medición de la eficiencia en las instituciones de educación superior, Fundación BBVA, Bilbao.

Menrad, K., 2004. Innovations in the food industry in Germany. Research Policy 33, 845-878.

Metcalfe, J.S., 2002. Equilibrium and Evolutionary Foundations of Competition and Technology Policy: new Perspectives on the Division of Labour and the Innovation Process, CRIC Working Papers series, University of Manchester.

Olazarán, M., Lavía, C., Otero, B., 2004. ¿Hacia una segunda transición en la ciencia? Política científica y grupos de investigación. Revista Española de Sociología 4, 143-172.

Pedersen, K.M., 1977. A Proposed Model for Evaluation Studies. Administrative Science Quarterly 22(2), 306-317.

Revilla, E., Sarkis, J., Modrego, A. 2003. Evaluating performance of public-private research collaborations: a DEA analysis. Journal of Operational Research Society 54, 165-174.

Rip, A., Nederhof, A.J., 1986. Between Dirigism and Laissez-Faire: Effects of Implementing the Science Policy Priority for Biotechnology in the Netherlands. Research Policy 15, 253-268.

Shapira, P., Kuhlmann, S., 2003. Learning from Science and Technology Policy Evaluation, Edward Elgar, Cheltenham.

Shephard, R.W., 1970. Theory of Cost and Production Functions, Princeton University Press, New Jersey.

Tassey, G., 2003. Methods for Assessing the Economic Impacts of Government R\&D. Planning Report 03-1, National Institute of Standards and Technology (NIST), US Department of Commerce.

Thomson, R.G., Dharmapala, P.S., Thrall, R.M., 1993. Importance for DEA of Zeros in Data, Multipliers, and Solutions. Journal of Productivity Analysis 4, 379-380. 
Treasury Board of Canada, 2002. Program Evaluation Methods: Measurement and attribution or Program Results, Minister of Public Works and Government Services, Published by Public Affairs Branch.

Van der Meulen, B., Rip, A., 2000. Evaluation of societal quality of public sector research in the Netherlands. Research Evaluation 8(1), 11-25.

Van Raan, A.F.J., 2000. R\&D evaluation at the beginning of the new century. Research Evaluation 8(2), 81-86.

Zofío, J.L., Prieto, A.M., 2006. Return to Dollar, Generalized Distance Function and the Fisher Productivity Index. Spanish Economic Review 8, 113-138.

\footnotetext{
${ }^{\mathrm{i}}$ This paper has benefited from conversations with Ignacio Fernández-de-Lucio, and the recommendations of two anonymous referees, to whom we are grateful for his comments and suggestions. The authors are responsible for any errors. We are indebted to Cynthia Little for her help with the language-editing of the text.
} 